\title{
The Multiply Motivated Self
}

\author{
Constantine Sedikides \\ University of North Carolina at Chapel Hill \\ Michael J. Strube \\ Washington University
}

Research on self-evaluation revolves around four major themes: How many motives guide self-evaluation, in what circumstances does each motive become activated, are motives differentially prevalent in different people, and how can research on the selfevaluation motives become integrated? The discussion is structured on the basis of these four themes.

$\mathbf{E}$ ither out of intellectual curiosity (e.g., 'What kind of person am I?"), as a consequence of interpersonal feedback in their daily lives (e.g., evaluations from teachers, employers, or leisure activity partners), or because of the unavoidable force of life events (e.g., new occupation, involvement in a romantic relationship, chronic illness), people may wonder how socially fit are their personality traits, how appropriate are their behaviors, how adequate are their skills and talents, or how fulfilling are their goals, personal relationships, group memberships, and lifestyles. Whenever people engage in subjective and valenced (i.e., good/bad) judgments of aspects of their self-concepts, they engage in self-evaluation.

The self-evaluation process can result in substantial benefits for the individual, particularly better selfunderstanding. This is likely to lead to more successful self-regulation and coping; to more informed choices of friends, romantic partners, and social groups; to more beneficial choices of occupational settings, hobbies, and interests; and to the selection of more fitting long-term goals. In other words, along with better self-understanding comes a greater likelihood of positive outcomes.

Because of its presumed critical role in human functioning, the topic of self-evaluation has attracted the persistent and keen interest of social and personality psychologists. Four major themes run through selfevaluation research. First, how many motives have been empirically supported as guides to self-evaluation? Second, in what circumstances does each motive become activated? Third, are motives differentially prevalent in different people? Fourth, how can research on the selfevaluation motives become integrated? We use these themes to structure the discussion that follows and end with some suggestions about the direction of future research.

\section{HOW MANY MOTIVES GUIDE} SELF-EVALUATION? 3 PLUS OR MINUS 1

To date, three major self-evaluation motives have dominated work in this area: self-enhancement, selfverification, and self-assessment. The self-enhancement motive refers to people's desire to enhance the positivity or decrease the negativity of the self-concept. The selfverification motive refers to people's desire to confirm and maintain the self-concept, be it positive or negative. The self-assessment motive refers to people's desire to re duce uncertainty about the self-concept regardless of whether the uncertainty reduction process is likely to result in favorable or unfavorable implications for the self.

The evidence for the operation of the self-enhancement motive is impressive. People process, remember, and judge self-referent information in ways that maximize the positivity of the self-concept; they present themselves to others in a'socially desirable manner; and they choose social comparison targets that place the self in a favorable position (Brown, 1991; Brown \& Dutton, this issue; Taylor \& Brown, 1988, 1994; see also Sedikides \& Strube, 1995). Similarly impressive is the evidence for the opera-

Authors' Note: Correspondence concerning this article should be addressed to Constantine Sedikides, Department of Psychology, University of North Carolina at Chapel Hill, CB\# 3270, Davie Hall, Chapel Hill, NC 27514-3270. Electronic mail: DIONYSUS@UNC.EDU.

PSPB, Vol. 21 No. 12, December 1995 1330-1335

C(C1995 by the Society for Personality and Social Psychology, Inc. 
ation of the self-verification motive. People perceive, select, interpret, and recall information in a manner that confirms established self-conceptions. Furthermore, people behave in a self-verifying manner, selecting interaction partners who are likely to confirm their selfconceptions and responding to nonconfirming interaction partners in ways intended to set the record straight (Swann, 1983, 1990; Swann \& Schroeder, this issue; see also Sedikides \& Strube, 1995). The evidence in favor of the self-assessment motive is also substantial. People prefer and engage in tasks of high diagnosticity (i.e., those that accurately reflect their abilities and personality traits) as opposed to tasks of low diagnosticity (those that equivocally reflect their abilities and personality traits), oftentimes irrespective of whether the task is likely to lead to success or failure (Strube, Lott, Le-XuanHy, Oxenberg, \& Deichmann, 1986; Strube \& Roemmele, 1985; Trope, 1983, 1986; see also Sedikides \& Strube, 1995).

Recently, however, the status of the "big three" has been challenged by the argument, on one hand, that one of the motives may not be as important as previously thought (Brown \& Dutton, this issue) and the suggestion, on the other hand, that an additional motive should be added to the list (Taylor, Neter, \& Wayment, this issue).

\section{Two Motives Guide Self-Evaluation}

Brown and Dutton argue in this symposium that the lay and scientific belief in the accuracy of self-knowledge is simply not supported by research evidence; people are neither particularly interested in accurate self-assessment nor particularly accurate in their self-views. Brown and Dutton's claims are provocative because they challenge what has been essentially a bedrock belief in social and personality psychology.

To be sure, Brown and Dutton's claims are themselves open to challenge. For example, their claim that people are not interested in accurate self-assessment rests on their particular interpretations of research typically taken as evidence for the motive. Brown and Dutton argue, for example, that research claiming to support the self-assessment motive does not take into account the individual's belief in the likelihood of success. Hence this research essentially ignores the reasonable possibility that, when diagnostic information is sought regardless of success or failure, most individuals do not believe that failure is a likely outcome. Consequently, what is actually sought is information likely to put the self in a positive light. Strube et al. (1986) are cited as an example of such research, but those researchers did, in fact, ask participants for their perceived likelihood of success (Study 2). When these ratings were taken into account, evidence still supported self-assessment. Research by Dunning (this issue), in which prior success and failure (and thus, presumably, future expectations) were manipulated, similarly found evidence for self-assessment. The issue thus seems a bit murkier than Brown and Dutton claim. Nonetheless, we agree with Brown and Dutton that the evidence for accuracy strivings does not measure up to the alleged power and prevalence of this motive, and, to us, this raises a crucial issue. If an accuracy motive does not exist, is limited to rare life-and-death decisions, or emerges only in highly specific circumstances, then the widespread persistence of the accuracy myth and the implications of this myth deserve empirical scrutiny.

The second part of Brown and Dutton's argument is also controversial and equally in need of additional research attention. They argue that correlations between self-knowledge and other measures of that same knowledge (e.g., objective measures; reports by friends, spouses, and experts) are low and thus indicate little accuracy. That the correlations are low is indisputable, but whether this means low accuracy is another matter. Before we trust this "null hypothesis" interpretation, alternative explanations need to be studied more rigorously. Researchers in this area should learn a lesson from previous debates in social and personality psychology that rested on similar "low correlations" arguments, such as the alleged weak relations between attitudes and behavior (Wicker, 1969) and between personality and behavior (e.g., Mischel, 1968; see also Epstein, 1979). Both claims challenged bedrock beliefs. In both cases, however, careful study showed that the low empirical correlations did not imply a true lack of relation between attitudes and behavior or between personality and behavior. Instead, the low correlations reflected methodological, statistical, and conceptual problems. When these problems were addressed, the true nature of the relations emerged. Several parallels are too obvious to ignore. In the attitude-behavior area, for example, it was found that strong correlations emerged when attitudes and behavior were measured specifically and at equivalent levels of specificity (e.g., Aizen, 1988; Fishbein \& Aizen, 1975; see also Fazio, 1986). This is similar to the "differences in definition" argument in the accuracy debate-that is, that low correlations between selfreports and others' reports about a particular selfattribute reflect different definitions of the attribute in question. Brown and Dutton dismiss this argument, but we believe it deserves more careful attention. Another example comes from the personality-behavior area. In that case, some simple truths about measurement and multiple determinism (Ahadi \& Diener, 1989; Epstein, 1979, 1980; Strube, 1991) were found to account for the apparently low trait-behavior correlations commonly re - 


\section{PERSONALITYAND SOCIAL PSYCHOLOGY BULLETIN}

ported in the literature. Similar principles deserve study in the case of self-knowledge accuracy.

Again, our point is not to dismiss Brown and Dutton's arguments but instead to urge additional careful study, because the implications of their claims are so important! We also urge temperance in the level of accuracy held as the standard against which empirical relations are judged. Complete accuracy can be hard to attain; indeed, it is also probably unnecessary from a pragmatic standpoint. Instead, most people are probably "accurate enough"-that is, they are aware of the boundaries of their abilities. For example, the second author is an avid golfer who would probably give a biased estimate of his handicap (a benchmark measure of ability) ; he has never bothered to have it measured by sanctioned methods. But his beliefs about his golf skills are accurate enough that, to date, he has wisely not sought his fortunes on the PGA tour.

\section{Four Motives Guide Self-Evaluation}

On the other side of the "number of motives" question is emerging evidence that a fourth motive, selfimprovement, should be added to the list (Taylor, Neter, \& Wayment, this issue; see also Taylor \& Lobel, 1989; Wood \& Taylor, 1991). The evidence in support of this motive is encouraging and is certainly consistent with pressures in Western culture toward achievement and mastery. Importantly, people often strive for the longterm improvement of their skills and personality traits regardless of whether they possess an accurate (by an external criterion; Kruglanski, 1989) view of these attributes, suggesting that the motive is indeed conceptually distinct from other self-evaluation concerns. The research reported by Taylor et al. in this symposium further supports the conceptual distinctiveness of this motive. What is particularly interesting about this motive is its future orientation and thus its emphasis on gaining information relevant to a self that does not currently exist. Of course, the dynamic nature of the self has not escaped the attention of self-evaluation researchers. Regardless of the motivation to improve, individuals must still make strategic decisions about how best to use current skills and attributes, particularly decisions about which social and performance arenas to enter. Nonetheless, the self-improvement motive further underscores this dynamic feature of self-evaluation.

\section{IN WHAT CIRCUMSTANCES DOES}

\section{EACH MOTIVE BECOME ACTIVATED?}

The sound empirical support for the self-enhancement, self-verification, and self-assessment motives, as well as encouraging empirical support for the self-improvement motive, implies that each motive operates under certain circumstances. A clear understanding of the interplay of these motives and the beginnings of an integrative theory of self-evaluation can emerge only when we fully grasp the circumstances in which each motive becomes operative. Accordingly, the search for moderators has been an important part of self-evaluation research. Moderators are defined as variables that regulate the activation and relative prevalence of self-evaluation motives.

For example, task diagnosticity moderates, in part, the emergence of self-assessment versus self-enhancement. The self-assessment motive becomes activated when the task is high rather than low in diagnosticity; however, the self-enhancement motive becomes more operative when the task is high in diagnosticity of success (i.e., likely to reveal the person's strengths) rather than diagnosticity of failure (likely to reveal the person's weaknesses) . (For relevant discussions, see Brown, 1990; Brown \& Dutton, this issue; Strube et al., 1986; Strube \& Roemmele, 1985; Trope, 1980.) Attribute ambiguity also moderates the strength of these motives. Self-enhancement emerges in the case of ambiguous attributes, whereas selfassessment prevails in the case of unambiguous attributes (Brown, 1986; Brown \& Gallagher, 1992; Dunning, Meyerowitz, \& Holzberg, 1989; Felson, 1981). One demonstrated moderator of self-enhancement versus selfverification is type of responding. Self-enhancement predominates in affective responding, whereas selfverification predominates in cognitive responding (Shrauger, 1975; Swann, Griffin, Predmore, Sc Gaines, 1987). Finally, an example of a moderator of selfassessment versus self-verification is the certainty with which self-beliefs are held. Self-assessment concerns prevail when certainty is low, whereas self-verification concerns prevail when certainty is high (Sedikides, 1993).

Research on moderators reflects more faithfully the complexity of the self-evaluation process than does work that focuses exclusively on a single motive. Moreover, an emphasis on moderators exemplifies a highly efficient way to achieve rapid growth of scientific knowledge (Platt, 1964; Popper, 1970; see also Greenwald, Pratkanis, Leippe, Sc Baumgardner, 1986, and McGuire, 1973, 1983). Along these lines, research can further attempt to capture the simultaneous impact of multiple moderators. Dunning's article in this symposium is a good example. Dunning shows that attribute modifiability, attribute importance, and prior success or failure interact to predict preferences for information. In essence, a desire for information regardless of prior success or failure (i.e., self-assessment) emerges only when attributes are important and modifiable, a sensible result because the information gained, though potentially unflattering, can be used for future improvement. 
When attributes are important but not modifiable, selfenhancement predominates. This kind of research helps draw more succinctly the boundary conditions for the different motives.

The moderator research described thus far assumes, of course, that self-evaluation of some type is instigated; the moderators are then assumed to determine the direction it takes. The research of Taylor et al. (this issue) suggests an even more basic question: What instigates selfevaluation in the first place? Their work suggests that most self-evaluation arises from past threat or failure or from expectation of future threat or challenge. This is important for two reasons. First, it reminds us that people are not habitually engaged in self-evaluation; there is undoubtedly quite a bit of "downtime" when the self is not the object of attention and scrutiny. Second, that self-evaluation processes are engaged primarily in threatening situations suggests an important and basic purpose for self-evaluation: self-protection.

\section{ARE MOTIVES DIFFERENTIALLY PREVALENT IN DIFFERENT PEOPLE?}

Although self-evaluation is likely to be an important concern for everyone, the preferred style of acquiring self-knowledge likely exhibits reliable variation. Accordingly, another theme of self-evaluation research involves the "who" question (Roney \& Sorrentino, this issue): What kind of persons are more likely to be affected by each motive? Past work suggests that high-self-esteem individuals (Brown \& Gallagher, 1992), high self-monitors (Krosnick \& Sedikides, 1990), high self-handicappers (Strube \& Roemmele, 1985) , narcissists (Moil \& Rhodewalt, 1993), and Type Bs (Strube, Boland, Manfredo, \& Al-Falaij, 1987) are more likely than their counterparts (low-self-esteem individuals, low self-monitors, low selfhandicappers, nonnarcissists, and Type As) to be influenced by self-enhancement as opposed to selfassessment. Furthermore, uncertainty-oriented persons are more likely to be guided in their self-evaluation by self-assessment, whereas certainty-oriented persons are more likely to be guided by self-verification (Roney \& Sorrentino, this issue; for a similar view, see Strube \& Yost, 1993). A particularly important point made by Roney and Sorrentino is that the two orientations (and presumably any personality-based styles of self-evaluation) may essentially reflect different ways to achieve the same end state. This is important because it can appear at times that the motives run at cross-purposes. In the short run, that may be true, but it may also be true that a larger and more common purpose underlies all four motives. Indeed, that is the direction that recent integrative attempts have taken.

\section{INTEGRATIVE ATTEMPTS}

To date, very few attempts have been made to integrate the multiple motives into a coherent model. One problem that such an integrative attempt must confront is that the conceptual distinctiveness of the motives is not as sharp as individual descriptions would suggest. For example, self-assessment is often described as providing accurate information for optimum adaptiveness to the environment. But that should also provide optimal selfenhancement in the long run, because future threats to the self can be better anticipated and avoided, whereas performance arenas that favor one's skills can be strategically selected. Self-verification is based on the assumption that individuals prefer to maintain and bolster those aspects of the self about which they are most certain. But how did they become so certain about those self-attributes in the first place? Presumably, that certainty was won through self-assessment. And the resulting predictability and control seem to have fairly obvious self-enhancement consequences. Finally, what underlies the desire for selfimprovement? Assuming we seek to improve those skills for which improvement is a "good bet," then selfenhancement seems to be a likely outcome. It also seems likely that what constitutes a good bet for improvement is informed by insights obtained through self-assessment and self-verification (Dunning, this issue). Indeed, perhaps people strive to improve to force further clarification of skills (self-assessment). The point is that the motives are distinct only to a degree; they overlap greatly in their antecedents and consequences.

Given this overlap, it is tempting to argue that all motives are of equal importance. But Sedikides and Strube (1995) have proposed an integrative model, the self-concept enhancing tactician model (SCENT), that explicitly assigns a primary role in the self-evaluation process to self-enhancement concerns. In fact, selfverification and self-assessment concerns (and presumably self-improvement as well) are subsumed under selfenhancement. The emphasis on self-enhancement is based on the assumption that basic concerns about pleasure and pain, broadly defined, have made concerns about self-enhancement more primary to psychological functioning. The implication is that most self-evaluation attempts have self-enhancement (or positivity strivings, to use Swann and Schroeder's term) as an eventual goal. Space does not permit elaboration, but the SCENT model also deals with issues such as how the social context influences the manifestation of the motives, what is the nature of the sequential effects that the three motives probably have on the processing of self-relevant information, and how the motives affect self-evaluation from a developmental standpoint. The merits of the 


\section{PERSONALITYAND SOCIAL PSYCHOLOGY BULLETIN}

SCENT model await empirical scrutiny, but it does represent one attempt to capture the complexity of selfevaluation under one conceptual umbrella.

\section{A LOOK TO THE FUTURE}

As should by now be clear, much work remains before a full understanding of self-evaluation is attained. In addition to those already discussed, several avenues of work strike us as particularly productive. First, research on self-evaluation motives has progressed without adequate attention to the cognitive processes and resources necessary to carry out the evaluative attempts. An exception is the work by Swann and his colleagues. Swann and Schroeder, in this symposium, propose a model that specifies the sequence of motive activation on the basis of the cognitive resources needed and available. In the face of self-referent feedback, self-enhancement concerns arise first. They are followed by self-verification concerns provided that cognitive and motivational resources are available. A careful self-assessing cost-benefit analysis is the last stage of feedback processing, this stage also being contingent on the availability of cognitive and motivational resources. A similar three-stage model has been proposed byJussim, Yen, and Aiello (1995). What we find particularly interesting about these models is the primitive, low-resource, and nearly automatic role accorded to self-enhancement. This role is consistent with the assumptions of the SCENT model.

The cost-benefit analysis described by Swann and Schroeder underscores another neglected aspect of selfevaluation: the frame of reference. That is, over what time period are the consequences of a given self-evaluative attempt to be judged? To date, little empirical attention has been given to this important question. For example, if unflattering but diagnostic information is sought with the hope that it will allow long-term improvement and a greater likelihood of positive outcomes, then what constitutes 'long term"? The answer determines the judgment of whether seeking the unflattering information is a rational choice or an irrational and possibly masochistic one. Similarly, self-verification strategies defend the selfconcept against change and inconsistency, yet change is inevitable. The self evolves in response to changing social and physical demands. Within what time frame is "resistance to change" a sensible strategy? Our point is that the operation of the self-evaluation motives carries with it assumptions about their frames of reference that, to date, have not been articulated carefully.

The developmental emergence of the motives is also poorly understood, and the lifespan topography is uncharted territory. Early development and later aging force changes that have clear implications for the self (e.g., changing abilities, changing social networks, tran sitions from school to work and from work to retire ment), and little is known about how these changes influence self-evaluation. A broader focus on self-evaluation across the life span will create important opportunities to study self-evaluation in novel and interesting ways. Ir addition, even when a narrow age range is studied (typically college students), most discussions of selfevaluation ignore the substantial development that has preceded the particular measurement in question. For example, that most people overestimate their talents (the above-average effect) does not strike us as unusual or particularly inconsistent with the use of self-assessment and self-verification strategies. After all, over years of self-evaluation, one acquires a wealth of information about skills and limitations that presumably can be usec to select life settings (e.g., careers, hobbies, friends) that maximize outcomes. Consequently, the base rate for success in most domains is likely to be quite high for most people and likely to influence greatly their estimates of current standing and future success. It is true that mathematically most people cannot be above average, but the folly of such perceptions assumes equal life courses and comparable bases of information on which comparative judgments of ability are made. Given the idiosyncratic and highly selective opportunity niches that people construct and select, that assumption does not seem war-ranted. Our point is that moment-tomoment self-evaluation must be placed in its developmental context.

Self-evaluation research has captured the attention, imagination, and creativity of social and personality psychologists for a long time. The vibrant pace of selfevaluation research is guaranteed to last, as long as issues such as the ones above await resolution.

1. Indeed, our extensive comments might be taken as evidence for our sworn allegiance to the self-assessment camp. Quite the contrary, elsewhere we argue for the primary importance of self-enhancement (Sedikides \& Strube, 1995)

\section{REFERENCES}

Ahadi, S., \& Diener, E. (1989). Multiple determinants and effect size. journal of Personality and Social Psycholo gy, 56, 398-406.

Aizen, I. (1988). Attitudes, personality, and behavior. Chicago: Dorsey.

Brown, J. D. (1986). Evaluations of self and others: Self-enhancement biases in social judgments. Social Cognition, 4, 353-376.

Brown, J. D. (1990). Evaluating one's abilities: Shortcuts and stumbling blocks on the road to self-knowledge. Journal of Experimental Social Psychology, 26, 149-167.

Brown, J. D. (1991). Accuracy and bias in self-knowledge. In C. R. Snyder \& D. F. Forsyth (Eds.), Handbook of social and clinical psychot ogy: The health perspective (pp. 158-178). New York: Pergamon.

Brown, J. D., \& Dutton, K. A. (1995). Truth and consequences: The costs and benefits of accurate self-knowledge. Personality and Social Psychology Bulletin, 21, 1288-1296. 
Brown, J. D., \& Gallagher, F. M. (1992). Coming to terms with failure: Private self-enhancement and public self-effacement. Journal of Experimental Social Psychology, 28, 3-22.

Dunning, D. (1995). Trait importance and modifiability as factors influencing self-assessment and self-enhancement motives. Personality and Social Psychology Bulletin, 21, 1297-1306.

Dunning, D., Meyerowitz, J. A., \& Holzberg, A. D. (1989). Ambiguity and self-evaluation: The role of idiosyncratic trait definitions in selfserving assessments of ability. Journal of Personality and Social Psychology, 57, 1082-1090.

Epstein, S. (1979). The stability of behavior: I. On predicting most of the people most of the time. Journal of Personality and Social Psychology, 37, 1097-1126.

Epstein, S. (1980). The stability of behavior: II. Implications for psychological research. American Psychologist, 35, 790-806.

Fazio, R. H. (1986). How do attitudes guide behavior? In R. M. Sorrentino \& E. T. Higgins (Eds.), The handbook of motivation and cognition: Foundations of social behavior (Vol. 1, pp. 204-243). New York: Guilford

Felson, R. B. (1981). Ambiguity and bias in the self-concept. Social Psychology Quarterly, 44, 64-69.

Fishbein, M., \& Aizen, I. (1975). Belief, attitude, intention, and behavior: An introduction to theory and research. Reading, MA: Addison-Wesley.

Greenwald, A. G., Pratkanis, A. R., Leippe, M. R., \& Baumgardner, M. H. (1986). Under what conditions does theory obstruct research progress? Psychological Review, 93, 216-229.

Jussim, L., Yen, H., \& Aiello, J. R. (1995). Self-consistency, self-enhancement, and accuracy in reactions to feedback. Journal of Experimental Social Psychology, 31, 322-356.

Krosnick,J.A., \& Sedikides, C. (1990). Self-monitoring and self-protective biases in use of consensus information to predict one's own behavior. Journal of Personality and Social Psychology, 58, 718-728.

Kruglanski, A. W. (1989). The psychology of being "right": The problem of accuracy in social perception and cognition. Psychological Bulletin, 106, 395-409.

McGuire, W. J. (1973). The yin and yang of progress in social psychology: Seven koan. Journal of Personality and Social Psychology, 26, 446456 .

McGuire, W. J. (1983). A contextualist theory of self-knowledge: Its implications for innovation and reform in psychological research. In L. Berkowitz (Ed.), Advances in experimental social psychology (Vol. 16 , pp. 1-47). New York: Academic Press.

Mischel, W. (1968). Personality and assessment. New York: Wiley.

Morf, C. C., \& Rhodewalt, F. (1993). Narcissism and self-evaluation maintenance: Explorations in object relations. Personality and Social Psychology Bulletin, 19, 668-676.

Platt, J. R. (1964). Strong inference. Science, 146, 347-353.

Popper, K. (1970). Normal science and its dangers. In I. Lakatos \& A. Musgrave (Eds.), Criticism and the growth of knowledge (pp. 51-58). Cambridge: Cambridge University Press.

Roney, C. J., \& Sorrentino, R. M. (1995). Self-evaluation motives and uncertainty orientation: Asking the "who" question. Personality and Social Psychology Bulletin, 21, 1319-1329.

Sedikides, C. (1993) . Assessment, enhancement and verification determinants of the self-evaluation process. Journal of Personality and Social Psychology, 65, 317-338.

Sedikides, C., \& Strube, M. J. (1995). Motivated self-evaluation: To thine own sef be good, to thine own self be sure, and to thine own self be true. Manuscript submitted for publication.

Shrauger, J. S. (1975). Responses to evaluation as a function of initial self-perceptions. Psychological Bulletin, 82, 581-596.
Strube, M. J. (1991). Multiple determinants and effect size: A more general method of discourse. journal of Personality and SocialPsychot ogy, 61, 1024-1027.

Strube, M. J., Boland, S. M., Manfredo, P. A., \&Al-Falaij, A. (1987). Type A behavior and the self-evaluation of abilities: Empirical tests of the self-appraisal model. Journal of Personality and Social Psychology, 52, self-appraisc

Strube, M. J., Lott, C. L., Le-Xuan-Hy, G.M., Oxenberg,J., \& Deichmann, A. K. (1986). Self-evaluation of abilities: Accurate self-assessment versus biased self-enhancement. Journal of Personality and Social Psychology, 51, 16-25.

Strube, M. J., \& Roemmele, L.A. (1985). Self-enhancement, self-assessment, and self-evaluative task choice. Journal of Personality and Social Psychology, 49, 981-993.

Strube, M. J., \&Yost,J. H. (1993). Control motivation and self-appraisal. In G. Weary, F. Gleicher, \& K. Marsh (Eds.), Control motivation and social cognition (pp. 220-254). New York: Springer-Verlag.

Swann, W. B., Jr. (1983). Self-verification: Bringing social reality into harmony with the self. In J. Suls \& A. G. Greenwald (Eds.), Psychological perspectives on the self (Vol. 2, pp. 33-66). Hillsdale, NJ: Lawrence Erlbaum.

Swann, W. B., Jr. (1990). To be adored or to be known? The interplay of self-enhancement and self-verification. In E. T. Higgins \& R. M. Sorrentino (Eds.), Handbook of motivation and cognition: Foundations of socialbehavior (Vol. 2, pp. 408-448). New York: Guilford.

Swann, W. B., Jr., Griffin, J. J., Predmore, S. C., \& Gaines, B. (1987) The cognitive-affective crossfire: When self-consistency confronts self-enhancement. Journal of Personality and Social Psychology, 52, 881889

Swann, W. B., Jr., \& Schroeder, D.G. (1995). The search for beauty and truth: A framework for understanding reactions to evaluations. Personality and Social Psychology Bulletin, 21, 1307-1318.

Taylor, S. E., \& Brown, J. D. (1988). Illusion and well-being: A social psychological perspective on mental health. Psychological Bulletin, 103, 193-210

Taylor, S. E., \& Brown, J. D. (1994). Positive illusions and well-being revisited: Separating fact from fiction. Psychological Bulletin, 116, 21-27.

Taylor, S. E., \& Lobel, M. (1989). Social comparison activity under threat Downward evaluation and upward contacts. Psychological Review, 96, 569-575.

Taylor, S. E., Neter, E., \& Wayment, H. A. (1995). Self-evaluation processes. Personality and Social Psychology Bulletin, 21, 1278-1287.

Trope, Y (1980). Self-assessment, self-enhancement, and task preference. Journal of Experimental Social Psychology, 16, 116-129.

Trope, Y. (1983) . Self-assessment in achievement behavior. In J. M. Suls \& A. G. Greenwald (Eds.), Psychological perspectives on the self (Vol. 2, pp. 93-121). Hillsdale, NJ: Lawrence Erlbaum.

Trope, Y. (1986). Self-enhancement and self-assessment in achievement behavior. In R. M. Sorrentino \& E. T. Higgins (Eds.), The handbook of motivation and cognition: Foundations of social behavior ( Vol 1, pp 350-378). New York: Guilford.

Wicker, A. W. (1969). Attitudes versus actions: The relationship of verbal and overt behavioral responses to attitude objects. Journal of Social Issues, 25(4) , 41-78.

Wood, J. V., \& Taylor, K. L. (1991). Serving self-relevant goals through social comparison. In J. Suls \& T. A. Wills (Eds.), Social comparison: Contemporary theory and research (pp. 23-50). Hillsdale, NJ: Lawrence Erlbaum. 